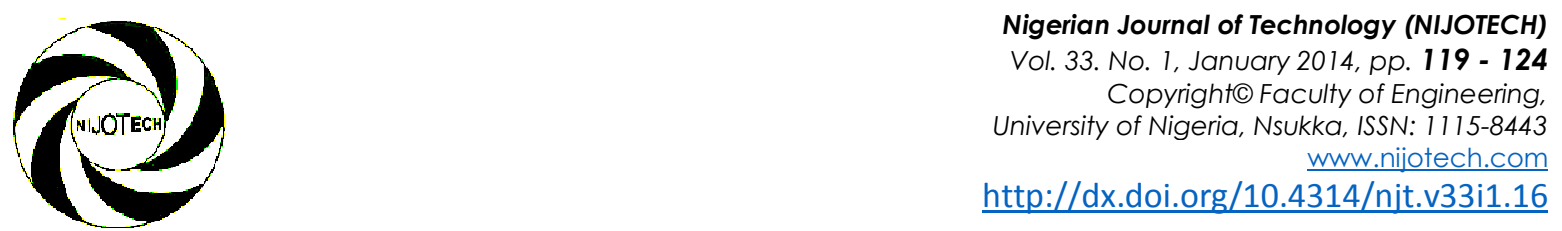

\title{
EVALUATION OF PROPERTIES OF BITUMEN MODIFIED WITH WASTE TYRE
}

\author{
O. J. Oyedepo ${ }^{1, *}$, S. D. Oluwajana ${ }^{2}$ \\ 1, 2,Department of Civil EngineERing, Federal University of TeChnology AKURE, Nigeria \\ E-mailaddresses:10yedepoo@yahoo.co.uk,2seunoluwajana@yahoo.com
}

\begin{abstract}
The research investigates the properties of bitumen modified with used tyre. Basic tests such as penetration, softening point, viscosity, flash and fire point and ductility test were carried out by using shredded waste tyre which varied from $0 \%$ to $20 \%$ by weight of $60 / 70$ penetration grade bitumen at $160^{\circ} \mathrm{C}$ using dry mix method. Penetration value decreased with addition of $20 \%$ tyre while increase in softening point, viscosity, flash and fire point were obtained with the corresponding values of $80.9^{\circ} \mathrm{C}$, $250.96 \mathrm{sec}$ and $189 / 280.12^{\circ} \mathrm{C}$ respectively. However, the values obtained exceeded the minimum values specified by American Standard for Testing and Materials (ASTM). The ductility value obtained with the addition of $6 \%$ and $14 \%$ tyre are $44.64 \mathrm{~cm}$ and $40.6 \mathrm{~cm}$ respectively. Thus, addition of $6 \%$ tyre content to bitumen is however suggested for best ductility value.
\end{abstract}

Keywords: Bitumen, Waste Tyre, Penetration, Softening Point, Viscosity, Ductility

1. Introduction

Tyre, an essential component of an automobile contributes greatly to solid wastes disposal problems in urban cities of developing nations. Also the indiscriminate dumping of waste tyres particularly in cities attract rodents and some dangerous reptiles that provides breeding grounds for mosquito [4], hence one of the means to solve the problem of waste tyres in the society is through it reuse and recycling. The disposal of tyres represents a major environmental issue throughout the world, since the same properties that make them desirable as tyres, most notably durability, also make their disposal and reprocessing difficult, they are almost immune to biological degradation [6]. Thus, they are categorized as hazardous waste. The hazards of waste tyres include- air pollution associated with open burning of tyres (particulates, odour, visual impacts, and other harmful contaminants such as polycyclic aromatic hydrocarbon, dioxin, and oxides of nitrogen); aesthetic pollution caused by waste tyres stockpiles and illegal waste tyres collecting and other impacts such as alterations in hydrological regimes when gullies and watercourses become waste sites [9]

The performance of the road pavement is determined by the properties of the bitumen which is the continuous phase and the only deformable component [10]. It is also a viscoelastic material with suitable mechanical and rheological properties for waterproofing and protective coverings for roofs and roads because of its good adhesion properties to aggregates [5]. This rheological weakness of conventional bitumen has generated an increasing interest in the use of polymer-modified binders to enhance conventional bitumen properties [7].

The development of modified bitumen materials to improve the overall performance of pavements has been the focus of several research efforts made over the past few decades, while researches on crumb rubber have been going on for the last three decades [4]. An estimated 5 million scrap tyres from trucks, cars and motorcycle existed in Nigeria in 1983 . With an annual generation rate of $15 \%$, each year about 700 - 850 thousand scrap tyres are added to the waste stream. About 15 million scrap tyres are now estimated to exist in Nigeria. As the country's economy and population grows, so do the amount and the types of scrap tyres being generated. Since most of these tyres which are either discarded indiscriminately or stocks piled are nonbiodegradable, they cause environmental problems [4]. Polymer modified binders has shown improved adhesion and cohesion properties, rutting resistance, thermal cracking, 
fatigue damage, stripping, and temperature susceptibility [5]. In the developed world, scrap tyres have been recycled through various methods including ground rubber, tyres derived fuel (TDF), reuse and retreating and several applications already exist for value added recovery from scrap tyres. These improvements have led polymer modified binders to be substituted for asphalt in many paving and maintenance applications. In many cases, they are selected to reduce life cycle costs [4].

The use of reclaimed ground tyres rubber as an additive in various types of bituminous construction does not only solve a waste disposal problem but offers the benefit of resource recovery, it is also of interest to the paving industry because of the additional elasticity imparted to the binder and pavement system [8].Hence, this research evaluates the basic properties of bitumen modified with waste tyres.

\section{Materials and Method \\ 2.1 Materials}

Materials used for this research are bitumen and waste tyres obtained locally within Akure. Also, $60 / 70$ penetration grade bitumen was obtained from FCC quarry in Akure, Ondo State Nigeria, while basic test such as Penetration, Softening Point, Viscosity, Ductility and, flash and fire point were carried out at both FCC Construction Company Laboratory and Civil Engineering Departmental Laboratory of the Federal University of Technology, Akure Nigeria. The basic properties of the bitumen used are shown in Table.1. The waste tyres were shredded, dried and ground into powdery form. The resulting powder obtained was then passed through 425 micron sieves while the finer particles obtained were then varied in proportion of $0 \%, 2 \%, 4 \%$, $6 \%$ till $20 \%$ by weight into the penetration grade bitumen at a constant temperature. However, bitumen with $0 \%$ additives was used as a control to study the variation caused in the properties of the bituminous material by adding varying quantity of the grounded waste tyres.

\subsection{Methods}

2.2.1 Mixing Method: There are two available methods for incorporating polymers into bitumen namely wet and dry mixing method. However this study employed dry mixing method. The selected bitumen was heated in an oven at $160^{\circ} \mathrm{C}$. The molten bitumen was then poured into 10 small containers and the net weight measured, then the powdered waste tyres was added by varying proportions and mixed thoroughly to produce a uniform mix. Table 2 shows the fraction by weight of tyres added.

Table 1: Basic Properties of the Selected 60/70

\begin{tabular}{lc}
\multicolumn{2}{c}{ Penetration Grade Bitumen } \\
\hline Test & Test Result \\
\hline Penetration & $68 \mathrm{pen}$ \\
Ductility & $42 \mathrm{~cm}$ \\
Softening Point & $54.5^{\circ} \mathrm{C}$ \\
Flash Point & $172^{\circ} \mathrm{C}$ \\
Fire point & $240^{\circ} \mathrm{C}$ \\
Viscosity & $142 \mathrm{sec}$ \\
\hline
\end{tabular}

Table 2: Percentage by Weight of Tyres Introduced

\begin{tabular}{|c|c|}
\hline Percentage (\%) Tyres added & Weight in grams (g) \\
\hline 2 & 2.4 \\
\hline 4 & 4.8 \\
\hline 6 & 7.6 \\
\hline 8 & 9.6 \\
\hline 10 & 12.0 \\
\hline 12 & 14.4 \\
\hline 14 & 16.8 \\
\hline 16 & 19.0 \\
\hline 18 & 21.6 \\
\hline 20 & 24.0 \\
\hline
\end{tabular}

\subsubsection{Test Methods}

Test carried out on the tyres modified bitumen with the respective standard used are listed below;

i. Penetration Test (ASTM D5 and AASHTO T49)

ii. Softening Point test (ASTM D 36)

iii. Ductility Test (ASTM D113 and AASHTO T5)

iv. Viscosity Test (ASTM D88 - 53)

v. Flash point and Fire point Test. (ASTM D2042 and AASHTO T44.)

Note: ASTM - American Association for Testing and Material,

AASHTO - American Association of state Highway and Transport Official.

\section{Results and Discussion 3.1 Penetration}

It is one of the most bitumen control test for grades of bitumen. It measures the consistency or hardness of bitumen. Figure 1 shows the variation in penetration values with various percentages of ground tyres used in bitumen.Penetration value of bitumen modified with ground tyres decreases in relation to the control bitumen (i.e. bitumen with $0 \%$ tyres content). This decrease in the value of 
penetration for tyres modified bitumen was influenced or caused by the presence of granular The value of penetration for the modified bitumen decreases as the proportion of ground tyre introduced increases as compared with the bitumen with no tyres content. Value of 66.8 pens and 52.4 pens were obtained for $2 \%$ tyres and $20 \%$ tyres inclusion respectively. Hence the decrease in the penetration value of modified bitumen is good suggesting that the presence of tyres granules will reduce rutting susceptibility of bituminous mix. However, this may have consequent effect on the flexibility of bitumen by making bituminous material much stiffer. tyres.

\subsection{Softening Point}

It measure the temperature at which a bitumen sample will no longer support the weight of $3.5 \mathrm{~g}$ steel ball. Figure 2 shows the softening point of tyres modified bitumen. Softening points values obtained for $2 \%, 4 \%, 6 \%, 8 \%$ and $10 \%$ tyres content are $57.14^{\circ} \mathrm{C}, 59.78^{\circ} \mathrm{C}, 62.42^{\circ} \mathrm{C}, 65.06^{\circ} \mathrm{C}$, and $67.7^{\circ} \mathrm{C}$ respectively; it does increases with amount of tyres content added to the bituminous materials while, a linear trend was observed for $12 \%$ to $20 \%$ tyres addition.

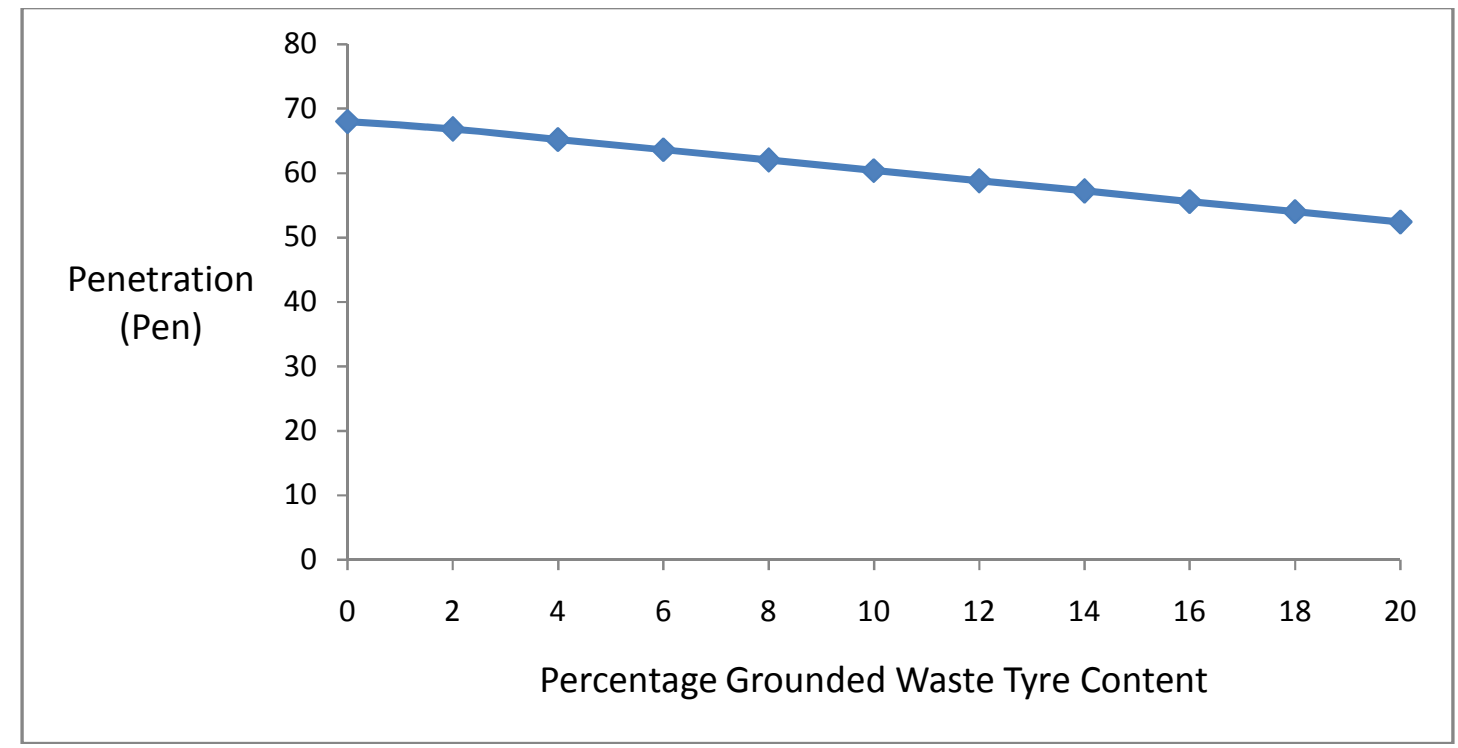

Figure 1: Penetration Test Values of Tyres Modified Bitumen

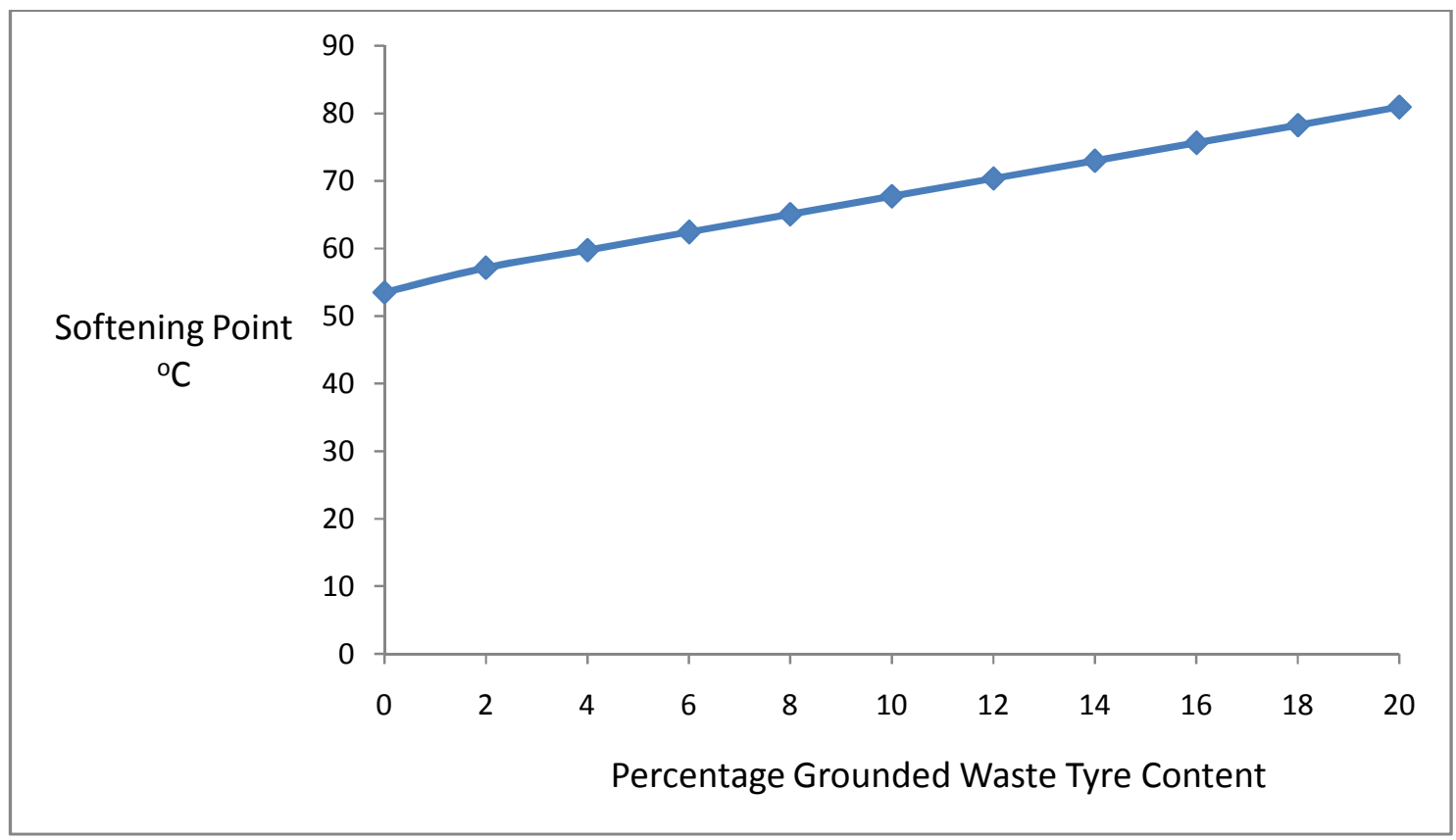

Figure 2: Softening Point of Tyres Modified Bitumen 
The trend observed in the softening point of tyres modified bitumen indicates that the addition of ground Tyres into bituminous material will increase its softening point value. This phenomenon suggested that the resistance of the bituminous binder to the effect of heat will increase which in turn will reduce the tendency of bitumen to bleed or softening in hot weather, hence with the addition of ground tyres, the adeverse effect of temperature on bituminous material will reduce. Similarly, the rate of rutting will decrease due to the increase in the stability and softening point of bitumen. Higher softening point of tyres modified bitumen will ensure that they will not flow during service. Therefore the higher the Tyres contents in bitumen, the higher the softening point hence the lesser the temperature susceptibility.

\subsection{Viscosity}

The viscosity test measures the consistency of an bitumen at some specified temperatures and are used to designate grades of bitumen. It is useful not only in ensuring that the material with the desired properties has been obtained but also a means of selecting binder for a specific purpose. The standard value of viscosity test for bituminous material as specified by American Association for Testing and Material (ASTM) and American Association of state Highway and Transport Official (AASHTO) is 100 seconds. However, as it can be seen in Figure 3, the viscosity of Tyres modified bitumen increases as the tyres content increases. The value obtained when compared to the standard value was observed to be more. Viscosity value obtained when $2 \%$ content was added was 144.79 seconds, 150.71 seconds for $4 \%, 158.1$ seconds for $6 \%$, and 166.95 seconds for $8 \%$ and 177.26 seconds for $10 \%$ respectively. This increasing trend of Viscosity of bitumen modified with tyres was observed up to the $20 \%$ tyres content inclusion investigated.

The Viscosity which is considered to be one of the important properties of bitumen binder was observed to increase as the percentage tyres content increase. This increase signifies that high proportion of ground tyres will cause tyres modified bituminous materials to stick with the aggregates when used in asphalt preparation.

\subsection{Ductility}

The ductility test (ASTM D113) measures the distance a standard asphalt sample will stretch without breaking under a standard testing condition $\left(5 \mathrm{~cm} / \mathrm{min}\right.$ at $\left.25{ }^{\circ} \mathrm{C}\right)$. The minimum cross section of the briquette before testing is 1 Square $\mathrm{cm}$. The result obtained showed that ductility tends to increase with increasing ground tyres content up to about $6 \%$ by weight of the bitumen used as value of $44.63 \mathrm{~cm}$ was obtained. High ductility occurred at $6 \%$ by weight of the tyres content introduced and decrease when 8\% tyres was used as modifier (see Figure 4). The increase in the ductility value of tyres modified bitumen up to $6 \%$ (corresponding to $44.63 \mathrm{~cm}$ ) can be attributed to the fact that tyres in the molten form is highly ductile hence when mixed with bitumen increase the ductility of the modified mix.

At percentage tyres content that was higher that $6 \%$ i.e. $8 \%$ there was a decrease in the ductility obtained with a value of $43.6 \mathrm{~cm}$ while, decreasing trend was observed up to $20 \%$ tyres content.

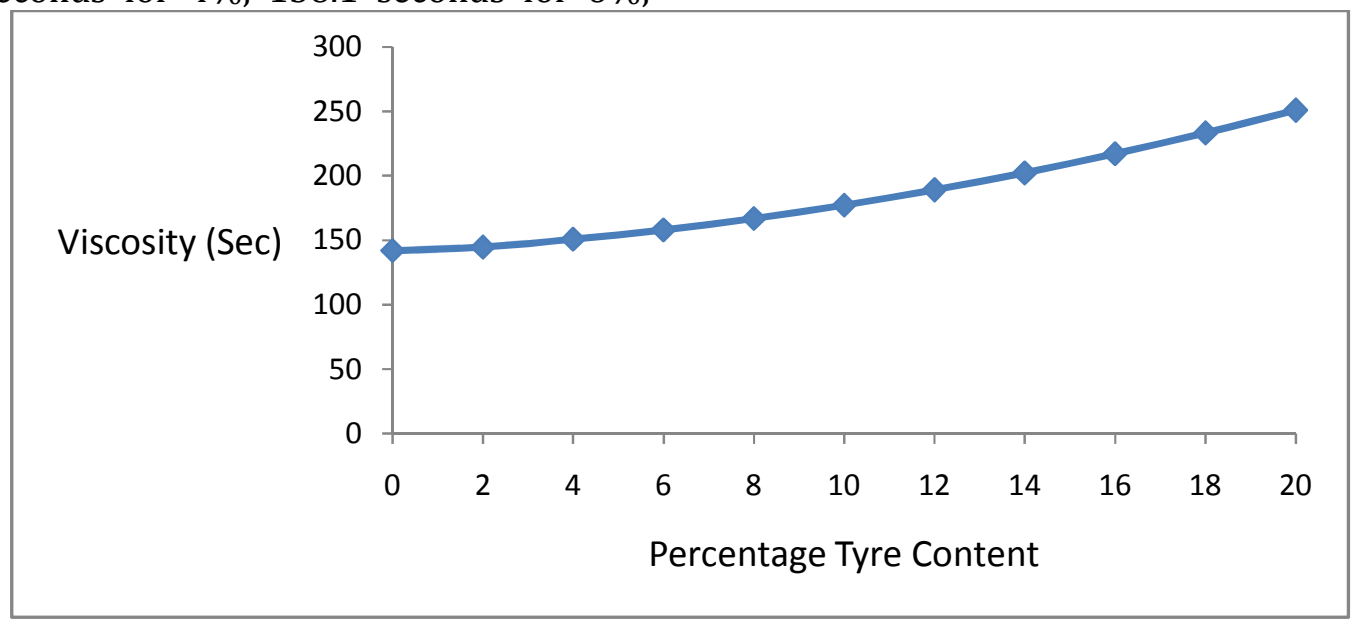

Figure 3: Viscosity of Tyres Modified Bitumen 


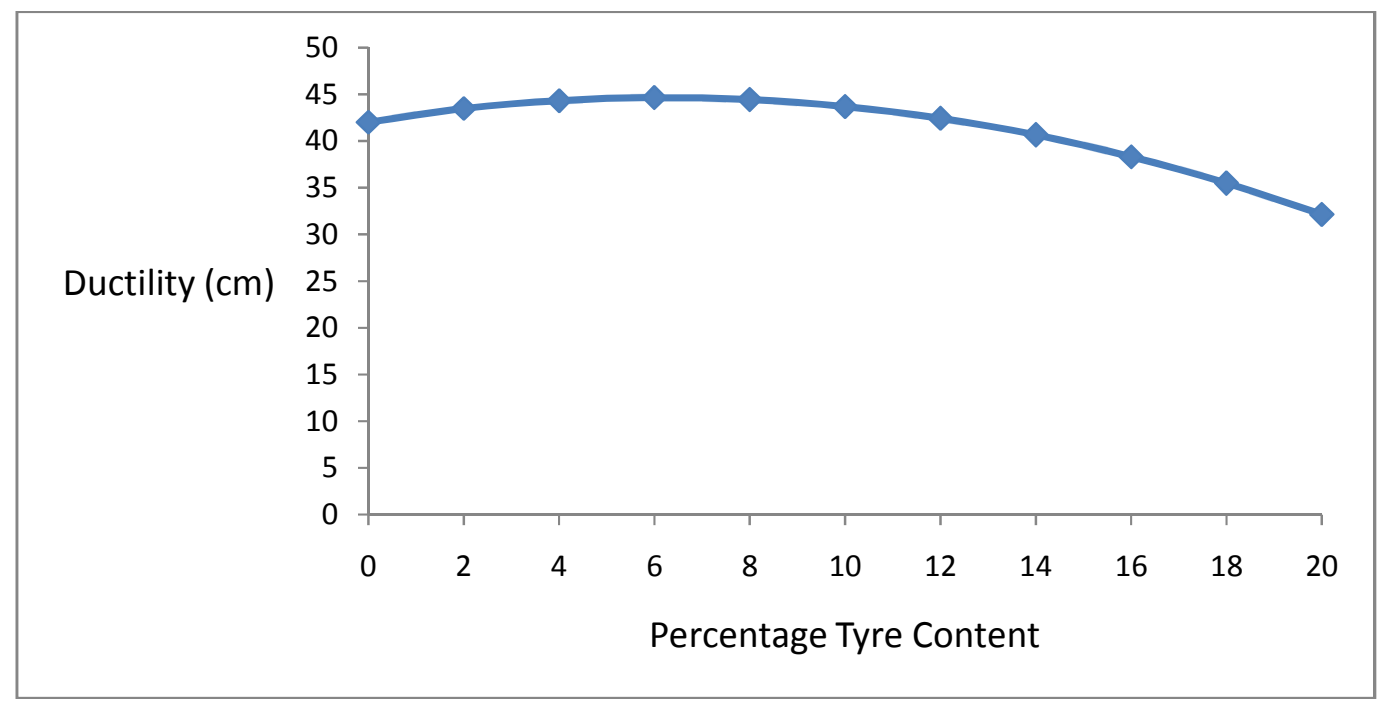

Figure 4: Ductility of Tyres Modified Bitumen

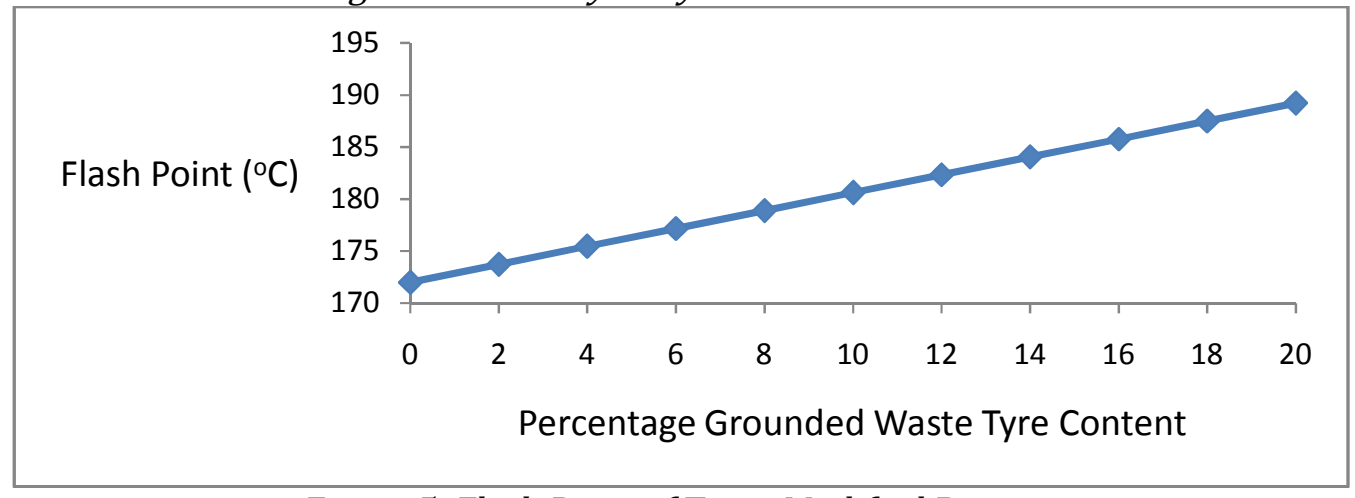

Figure 5: Flash Point of Tyres Modified Bitumen

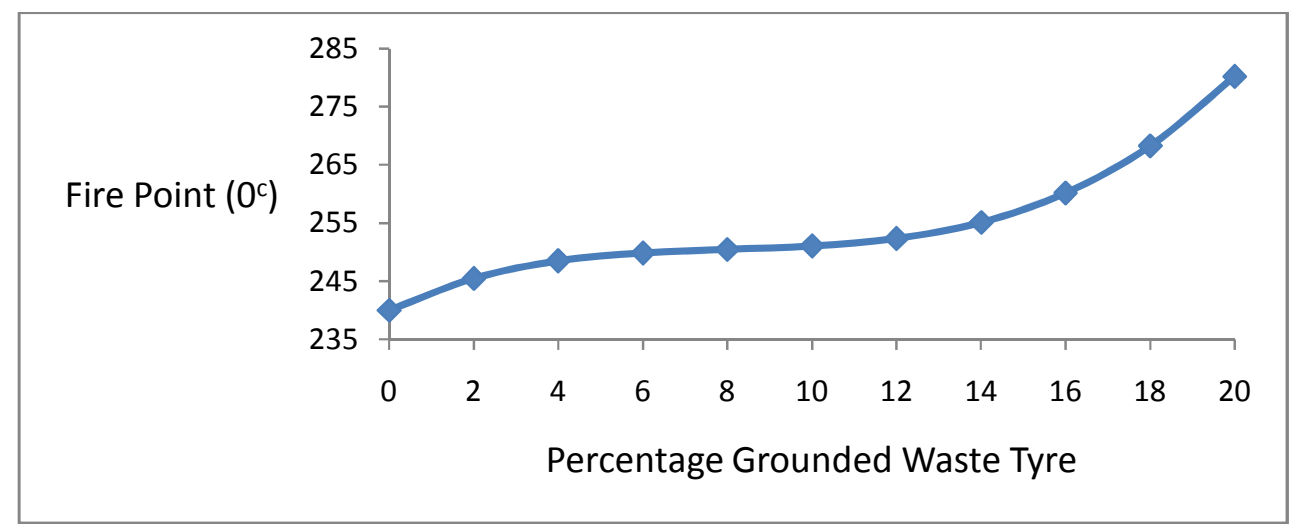

Figure 6: Fire Point of Tyres Modified Bitumen

The ductility of the modified bitumen drop below ASTM specified standard of $40 \mathrm{~cm}$ with the addition of $16 \%$ tyres content. This decreasing trend can be attributed to the difficulties in producing homogenous mix as the bitumen was unable to thoroughly dissolve the added tyres content added to it. Between $16 \%$ to $20 \%$ tyres inclusion, the ductility of the modified bitumen dropped below the specified value of $40 \mathrm{~cm}$. This implies that the use of tyres as modifier in bitumen must be limited to $6 \%$ for maximum performance as low ductility increases crack susceptibility.

\subsection{Flash and Fire Point}

Bituminous materials volatize when heated. At extreme temperature bitumen can release enough vapour to increase the volatile 
concentration to a point where it ignites (flash) when exposed to a spark or open flame. For safety reason the flash point of bituminous compound is tested under control. The fire point which occurs after flash is the temperature at which the material will sustain combustion. Figure 5 shows the flash and the fire point of tyres modified bitumen. As it can be seen clearly, the addition of tyres content increases the flash and fire point. ${ }^{\circ} \mathrm{C}$

As various proportions of tyres was added to the bitumen, the flash point increases exceeding the value of $170^{\circ} \mathrm{C}$ specified by ASTM standard. There was an increase in the flash point of the bituminous binder modified with tyres. An increase in the flash point of the bitumen from $172^{\circ} \mathrm{C}$ to $173.7^{\circ} \mathrm{C}$ was obtained when $2 \%$ tyres by weight bitumen was added. Similar increase was observed the tyres content of the bitumen was increased from $40 \%$ to $20 \%$ with the highest value obtained at $20 \%$ corresponding to $189.2^{\circ} \mathrm{C}$.

The result of the Fire point of modified bitumen increases from $2 \%$ to $20 \%$ with the highest value of $280.158{ }^{\circ} \mathrm{C}$ at $20 \%$. The increase in the flash point and the fire point of the tyres modified bitumen can be attributed to the difference in the ignition temperature of the two materials mixed i.e. tyres and bitumen as tyres ignites at higher temperature. This signifies that inclusion of tyres content into bituminous mix will likely reduce associated fire hazard.

\section{Conclusion and Recommendation}

Based on the laboratory test results, the bitumen mixture containing tyres produced high resistance to permanent deformation and was found to be highly resistant to rutting. The result of the penetration, ductility, viscosity, flash and fire point, and softening point test show a decrease in the consistency and increased in the resistance of the material to temperature changes. Thus, tyres modified bitumen will provide better resistance to pavement deformation and rutting due to higher softening point when compared to bitumen with $0 \%$ tyres content. Also, the use of tyres in bitumen will contributes to the reuse of waste tyres thereby enhancing the protection of the environment. Therefore, the use of waste tyres at $6 \%$ optimum mixture content is hereby recommended.

\section{References}

[1] ASTM, "Standard Test Method for Penetration of Bituminous Materials" D5-97, Annual Book of Standards, Vol.04.03, Easton, MD, USA, 2000.

[2] ASTM, "Test Method for Softening Point of Bitumen (Ring -and- Ball Apparatus)", D36 06, Annual, 2000.

[3] ASTM, "Test Method for Viscosity Determinations of Unfilled Asphalts Using the Brookfield Thermoset", 2000.

[4] Eisien F.A., Hymore F.K., and Ebewele R.O., "Application of Ground Scrap Tyre Rubbers in Asphalt Concrete Pavements", Indian Journal of Engineering and Material Sciences, Vol. 13, pp. $333-338,2006$.

[5] Kalantar N.Z., Mahrez A., and Karim M.R., "Properties of Bituminous Binder Modified with Waste Polyethylene Terephthalate", Proceeding of Malaysia University Transpiration Research Forum and Conferences, University Tenaga National, 21 December 2010.

[6] Mui E.L.K., Ko D.C.K, McKay G., "Production of Active Carbon from Waste Tyres. Carbon", No. 42, pp. 2789-2805, 2005.

[7]Mohamed A.A, Omar H., Hamzah M.O. and Ismail H., "Rheological Properties of Crumb Rubber Modified Bitumen Containing Antioxidant", Arabian Journal of Science and Engineering Vol. 24, No 1B, 2009.

[8] Roberts F.L., Kandhal P.S., Brown E.R., and Dunning R.L., "Investigation and Evaluation of Ground Tyres Rubber in Hot Mix Asphalt", NCAT Report No. 80-3, (1989).

[9] Rokade S., "Use of Waste Plastics and Waste Rubber Tyres in Flexible Highway Pavement", International Conference on Future Environment and Energy, IPCBEE Vol. 28, IACSIT Press, Singapore, 2012.

[10] Yuonne B., M. P. M., Yajaira R., "Polymer Modified Asphalt", Vision Technologica, Vol. 9, No. 1, pp. 3948,2001 